tenacity of a man with a love of discovery and scientific knowledge who was determined to succeed despite human weakness and natural obstacles. Aurousseau has now established an authentic text of Leichhardt's correspondence, opening the way for publication of his journals. As Leichhardt has remained a controversial figure in Australian history, this edition of his letters is an important beginning to the needed scholarly reappraisal of his life and work.

Harold Fruchtbaum

\section{RACE, SEX AND INTELLIGENCE}

\section{Negro and White Children}

A Psychological Study in the Rural South. By Earl E. Baughman and W. Grant Dahlstrom. Pp. xxiii +572 . (Academic Press: London and New York, July 1968.) $140 s$.

THIs remarkable book reports on a series of closely related psychological studies of ehildren in a segregated community in North Carolina. For a period of four years the authors led a team of Negro and white investigators who collected data from children, parents and teachers belong. ing to their own racial groups, relevant to the measurement and understanding of intelligence and academic achievement in boys and girls from kindergarten age to adolescence in an economically deprived community.

As one would expect, all children score somewhat below national norms, particularly after the age of 11 ; by and large, the girls in both racial groups outstrip the boys; the Negro scores of both sexes are with one or two exceptions below the white scores. It is almost an injustice to this book, however, to report these crude overall results. What makes these studies remarkable is the conception of intellectual functioning and development as embedded in other personal attributes as well as in the child's social environment (his family and the community). Accordingly, this is not just a testing exercise; the data presented stem from interviews with children, their mothers, peers and teachers; two types of intelligence tests; objective and projective personality tests; direct observations; and a variety of rating scales and sociometric choices. While the authors, of course, assume that intelligent actions and motivation are the result of the interaction of biological and environmental factors, they fully realize that we do not, as yet, have the methods to partial out these two components, with the result that "no one can prove that one race is innately inferior to another. Nor can it be proved that there are not racial differences in some behaviours attributable at least in part to genetic factors".

The work includes longitudinal studies over a period of three years and provides additional evidence for the spontaneous changes in measured $I Q$. About two-thirds of the Negro children undergo a change of IQ of at least 5 points, ranging from a gain of 19 points to a loss of 29 between the ages of 4 and 7 . A parallel longitudinal study was conducted with white children between the ages of 11 and 15; here more than half showed spontaneous changes of at least 5 points, ranging from a gain of 29 to a loss of 24 .

The crucial question is, of course, what accounts for such shifts? There is some evidence to show that Negro children who attend kindergarten develop at a rate equal to that of white children, while without such training their development is slower than that of white children; children from the relatively more privileged families perform better than those from more deprived families. Included in the book is a detailed account of the investigators' deliberate effort to accelerate the motivational and intellectual growth of some of the children. In contrast to the head-start programmes, the investigators decided to conduct their weekly sessions with each child in the child's house; this is not only less costly but involves the considerable advantage of being able to teach the mother while teaching the child on how to awaken interest in learning in apparently uninterested and unmotivated children. Even though the measurement of progress in this project was inevitably less objective than in the rest of the book, the detailed description of the plan of action, its rationale and its impact present a fascinating chapter.

Some of the personality attributes of these children are less comprehensively investigated and hence lead sometimes to inconclusive results which further research will, I hope, refine and develop. As one of its virtues, the book is scrupulously precise and detailed on methods and scoring procedures; for example, on how to obtain scores for achievement motivation, where it is on so low a level that McClelland's well-known procedure would yield a uniform zero. By the same token, the amount of technical detail makes minor criticisms easy (why, for example, collect so many questionnaire data which are not and perhaps cannot be meaningfully analysed?) and will bore the non-psychologist reader unless he is prepared to pick and choose.

Altogether, however, this is an important book which sets a new high standard for the study of the complex relation between race, sex and measured intelligence.

MARIE JAHODA

\section{CHANGING FOR THE BETTER}

Beyond the Therapeutic Community

Social Learning and Social Psychiatry. By Maxwell Jones. Pp. xxii +150 . (Yale University Press: New Haven and London, July 1968.) 58s.

THE basic concept of the therapeutic community is that getting an individual to join a group, in which certain desired attitudes or behaviours are valued, will help to charge him for the better. Maxwell Jones first applied this idea to people who had employment and other social difficulties and subsequently extended it to those admitted to mental hospitals or prisons. He now further broadens it to take in more general educational problems. $\mathrm{He}$ devotes detailed attention to the problems of leadership in a therapeutic community and indicates how the system of group appraisal works in his own Scottish psychiatric hospital. Jones needs to assume that "the psychiatric hospital can be seen as a microcosm of society outside", because otherwise much of the text would appear irrelevant to the larger issues he wishes to discuss. Nevertheless, he does not draw upon the very large and relevant literature concerning the use and abuse of political power, although parallels seem to arise on every page, partienlarly when he is discussing the problems of leadership, consensus, decision-making, confrontation and crisis. Jones argues in favour of "multiple" leadership (based, however, on the charisma of one leader). The group will find itself (so long as the potential Trotskys contain the moselves and the potential Red Guards are not overenthusiastic) using the leader as their "vehicle of expres. sion". The value or otherwise of formal checks and balances and a formal opposition are not discussed. It is assumed that "a group identity" will emerge "that transcends individual identity"-- democracy will then bo fully achieved.

Coming down from these higher planes to the actual treatment of patients, ono is surprised to see no attempt to deal with the rapidly growing scientific literature on social psychiatry, in which claims for social treatments are subjected to the same critical analysis and experimentation as those for more traditional therapies. In the long run, the therapeutic community as defined by Maxwell Jones must prove itself in practical terms. At the very least it must be shown that people who are exposed to it are better off in some measurable way than people who 